\title{
FORMULATION OF NANOPARTICLES OF TELMISARTAN INCORPORATED IN CARBOXYMETHYL CHITOSAN FOR THE BETTER DRUG DELIVERY AND ENHANCED BIOAVAILABILITY
}

\author{
UPASANA YADAV ${ }^{1 *}$, ANGSHUMAN RAY CHOWDHURI ${ }^{2}$, SUMANTA KUMAR SAHU ${ }^{2}$, NUZHAT HUSAIN ${ }^{3}$, QAMAR REHMAN ${ }^{4}$
}

${ }^{1}$ Department of Biotechnology, School of Applied Sciences, Amity University, Lucknow, Uttar Pradesh, India. ${ }^{2}$ Department of Applied Chemistry, Indian School of Mines, Dhanbad, Jharkhand, India. ${ }^{3}$ Department of Pathology, Dr. Ram Manohar Lohia Institute of Medical Sciences, Lucknow, Uttar Pradesh, India. ${ }^{4}$ Department of Biotechnology, Amity University, Lucknow, Uttar Pradesh, India. Email: profupasana.yadav@gmail.com

Received:14 April 2017, Revised and Accepted: 29 May 2017

ABSTRACT

Objective: In this study, we have made an attempt to the developed formulation of nanoparticles (NPs) of telmisartan (TLM) incorporated in carboxymethyl chitosan (CMCS) for the better drug delivery and enhanced bioavailability.

Materials and Methods: The NPs size and morphology were investigated by high-resolution transmission electron microscopy and field emission scanning electron microscopy, respectively. The crystal structures and surface functional groups were analyzed using X-ray diffraction pattern, and Fourier transform infrared spectroscopy, respectively.

Results: To increase the solubility of TLM by targeted delivery of the drug through polymeric NPs is an alternative efficient, option for increasing the solubility. TLM nanosuspension powders were successfully formulated for dissolution and bioavailability enhancement of the drug. We focused on evaluating the influence of particle size and crystalline state on the in vitro and in vivo performance of TLM.

Conclusion: In summary, we have developed a new approach toward the delivery of poorly water-soluble drug TLM by CMCS NPs. The particles having a good drug loading content and drug encapsulation efficiency. The cytotoxicity of the synthesized NPs is also very less.

Keywords: Telmisartan, Nanoparticle, Carboxymethyl chitosan, Transmission electron microscopy, Scanning electron microscopy.

(C) 2017 The Authors. Published by Innovare Academic Sciences Pvt Ltd. This is an open access article under the CC BY license (http://creativecommons. org/licenses/by/4. 0/) DOI: http://dx.doi.org/10.22159/ajpcr.2017.v10i9.19162

\section{INTRODUCTION}

The administration of drug telmisartan (TLM) by the oral route is desirable but difficult due to the variable $\mathrm{pH}$ of the gastrointestinal tract. The presence of enzymes such as pepsin and the highly acidic $\mathrm{pH}$ in the stomach can cause protein degradation. There is a substantial loss of drug activity due to pancreatic enzymes secreted by the lumen of the intestine and also by membrane-bound brush-border enzymes. Finally, the physical barrier of the intestinal cells must be crossed before a drug can reach the circulation. To reduce all the above problems, nanoparticles (NPs), a new drug delivery system has been developed [1-3]. For medical purposes NPs are an attractive material which depends on their important and unique properties, such as their surface to mass ratio is much larger than that of other particles, their quantum properties and their ability to absorb and carry other compounds [4-6]. NPs of polymer not only protect the bioactive substance but also facilitate the control release of the material in delivering system [7-10]. In comparison to other polymer, chitosan is used extensively in drug delivery applications [11-16]. Chitosan can be produced in a different form such as fiber, film, paste, powder due to its reactive nature $[17,18]$. The solubility of chitosan depends on the free distribution of amino and $N$-acetyl group [19]. Chitosan slowly metabolizes into less harmful metabolite (amino sugars) which are completely absorbed by human body [20]. Carboxymethyl chitosan (CMCS) can be obtained by direct alkylation of chitosan. The CMCS achieved can be in various types: $N, O$-CMCS and $N, N$-CMCS, $\mathrm{N}$-CMCS, O-CMCS. Different degree of substitution and different reaction conditions will result in the $\mathrm{N}$ versus $\mathrm{O}$ selectivity. CMCS is soluble in water at neutral $\mathrm{pH}$. It possesses large hydrodynamic volume, high viscosity, film and gel forming capabilities and the other useful properties, such as biodegradation, biological activity, and low toxicity, biocompatibility all the above properties makes it an attractive option in relation with its use in drug delivery, food, and cosmetics. To synthesize O-CMCS NP we have used $\mathrm{CaCl}_{2}$ as crosslinking agent. To achieve targeting property, $\mathrm{CaCl}_{2}$ is incorporated into the amphiphillic polymers through coupling reaction between the - $\mathrm{COOH}$ group of CMCS through 2, 2'-(ethylenedioxy)-bis-(ethylamine) to obtain the final product. At neutral $\mathrm{pH}$ is expected to constitute a hydrophobic core of self-assembled NPs which can serve as a depot for hydrophobic drugs. At acidic $\mathrm{pH}$, the free amines group of chitosan is to be protonated, causing disassembles of the NPs and eventual release of drugs [21-23]

Chitosan, a copolymer of $\mathrm{N}$-acetyl-D-glucosamine and glucosamine linked by glycosidic bonds, is the second plentiful biomass produced by deacetylation of chitin. It can absorb toxic metals such as mercury, cadmium, and lead. It also has following properties such as antimicrobial, immuno-stimulation, coagulation ability, good adhesion, bio-degradability, biocompatibility, hemostatic, and fungistatic. In view of the above properties, chitosan has been used as a biomaterial for drug delivery, gene delivery, and other biomedical application [24-28]. For the preparation of mucoadhesive formulation, chitosan has been used [29-32]. It improves the rate of dissolution of poorly soluble drug for the targeted drug delivery and enhances the absorption of the peptide. Cell adhesion and potential cell uptake of NPs of chitosan should be efficient due to its positive charge which is attracted by negatively charged cell membranes. Since it is poorly soluble in water and inorganic solvents which limit its wide applications. Chitosan has positive charges $\left(-\mathrm{NH}_{3}^{+}\right)$thus at relatively low $\mathrm{pH}(<6.0)$ are soluble in dilute aqueous solutions, but as the $\mathrm{pH}$ increases they lose their charge and precipitate from the solution due to de-protonation of the amino group [33-37].

For the prevention and treatment of hypertension TLM an, angiotensin II receptor antagonist is used. TLM is less soluble and highly permeable 
because it belongs to Class II drug. The low solubility of the drug in biological fluids which results into poor bioavailability after oral administration is one of the big problems [38-41]. The solubility of TLM in water is very low, i.e., $0.078 \mathrm{mg} / \mathrm{ml}$ in water. Poor bioavailability after oral administration of the TLM is due to its bioavailability that is $42-58 \%$, and biological half-life is only 24 hrs. Thus, increasing dissolution and aqueous solubility of TLM is of therapeutic importance [42-49]. Various approaches for enhancing solubility and oral efficacy of TLM used were solid dispersion and inclusion complexation [50-52]. None of the above approaches offered an adequate improvement in therapeutic potential due to the dosage form limitations itself. Thus, we used the CMCS polymers to load TLM, which have not been used to best of our knowledge and there is no report about the use of this based drug delivery. In light of these, the aim of the present investigation was done to design and develop novel nanoparticulate solid oral dosage forms of TLM by incorporating it into the CMCS.

In this research, the solubility and bioavailability of TLM in conjugation with various carriers using various methods were studied. Besides this solubility and dissolution study, the various evaluation methods were carried out to determine the physicochemical properties of solid dispersions and physical mixture in comparison to pure drug. To increase the solubility and for targeted drug delivery of TLM use of polymeric NPs is an alternative efficient, option. In this study, TLM nanosuspension powders were successfully formulated for dissolution and bioavailability enhancement of the drug. We focused on evaluating the influence of crystalline state and particle size on the in vitro and in vivo performance of TLM.

\section{MATERIALS AND METHODS}

\section{Materials}

\section{Drugs and chemicals}

Purchases were as follows: Chitoson, 3-(4,5-dimethylthiazol-2-yl)2,5-diphenyltetrazolium bromide (MTT), TLM, and monochloroacetic acid were purchased from Sigma-Aldrich (USA). Calcium chloride, isopropanol were obtained from Merck India. Drug solutions were freshly prepared in millipore water. Organic solvents such as methanol and ethanol were purchased from Qualigens Fine Chemicals (Mumbai). Dimethyl sulfoxide (DMSO) and $N, N^{\prime}$-dimethyl formamide were obtained from Merck India. Fetal bovine serum and minimum essential medium were procured from Hyclone (USA) and Himedia (India), respectively. All chemicals were used without further purification.

\section{Methods}

\section{General procedure for preparation of CMCS}

CMCS were synthesized using chitosan (1.0 g) was swelled in 50\% $(\mathrm{w} / \mathrm{v})$ sodium hydroxide solution $(40 \mathrm{ml})$ at $0^{\circ} \mathrm{C}$ for overnight. Further chitosan was washed with isopropanol and dissolve in isopropanol $(30 \mathrm{ml})$. A reaction mixture of monochloracetic acid (3.0 g) and isopropanol $(5 \mathrm{ml})$ was added dropwise into the chitosan mixture and reacted for $12 \mathrm{hrs}$ at $40^{\circ} \mathrm{C}$. The reaction was stopped by adding $70 \%$ ethyl alcohol $(25 \mathrm{ml})$. The solid was filtered and washed with ethyl alcohol and vacuum dried at room temperature. The resulted product was sodium salt of CMCS [53].

\section{Preparation of CMCS NPS}

CMCS NPs were synthesized by ionotropic gelation of CMCS solution with calcium chloride solution. About $0.5 \%$ CMCS solution was prepared in distilled water. The solution ( $5 \mathrm{ml}$ ) was added in $1.5 \%$ $\mathrm{CaCl}_{2}(1 \mathrm{ml})$ solution under continuous stirring. The resulting NPs were purified by centrifugation for $10 \mathrm{~min}$ at 15,000 rpm and lyophilized. A diagrammatical representation is given in Fig. 1 for better insight into the development of nanoparticles (NPs).

\section{Drug loading into NPS}

TLM $(1 \mathrm{mg} / \mathrm{mL})$ in the poorly water soluble drug was dissolved in glacial acetic acid solution $(10 \mathrm{ml})$. CMCS NPs $(10 \mathrm{mg})$ were

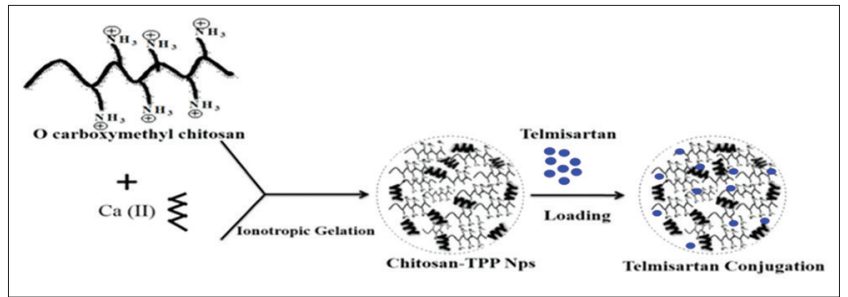

Fig. 1: Schematic representation of synthetic procedure of carboxymethyl chitosan-telmisartan

introduced into the previously prepared drug solutions. The solution was shaken in an orbital shaker for $24 \mathrm{hrs}$. The suspension was then centrifuged at 15,000 rpm for 20 minutes to separate the NPs from the solutions. The procedure was repeated 3 times to eliminate any unloaded TLM from the suspension. The amount of loaded TLM was measured spectrophotometrically at $295 \mathrm{~nm}$ with a ultraviolet (UV)1700 spectrophotometer (Shimadzu). The drug loading content and entrapment efficiency were calculated according to the following equations.

$$
\text { Drug loading contents }(\%)=\frac{\text { Weight of drug in nanoparticles }}{\text { Weight of nanoparticles taken }} \times 100
$$

Drug entrapment efficiency $(\%)=\frac{\text { Weight of drug in nanoparticles }}{\text { Weight of nanoparticles taken }} \times 100$

\section{Characterization of CMCS nonoparticles}

\section{Particle size and zeta potential measurement}

Mean particle size its distribution were determined using dynamic light scattering (DLS) technique. Zeta potential was evaluated by measuring electrophoretic mobility of the particle using a laser-based multiple angle electrophoresis analyzer. TLM NPs were sufficiently diluted with deionized water to reduce the count rate up to 100-250 kcps and analyzed by employing Malvern Zetasizer (Nano ZS, Malvern Instruments, UK). Observations were recorded in triplicate for each sample at $25 \pm 1^{\circ} \mathrm{C}$.

Particle size measurement by transmission electron microscopy (TEM) and scanning electron microscopy (SEM)

Particle's morphological characterization of TLM NPs was executed by SEM and TEM. Samples for SEM studies were prepared by clinging the NPs on a double adhesive tape stuck to an aluminium stub and were coated with gold and palladium under an argon atmosphere utilizing a high-vacuum eveporator (Polaron SEM coating system). Samples were scanned through an electron microscope (EVO-50, ZEISS; UK) and photomicrographs were captured. For TEM, a drop of optimized NP suspension in aqueous solution was placed on a carbon film coated on a copper grid and freeze dried. Then, NPs were observed at $80 \mathrm{kV}$ using Tem TECNAI G ${ }^{2} 20$ S-TWIN (FEI Netherlands) instrument, from Indian Institute of Toxicology Research (IITR), Lucknow.

\section{Aggregation state of TLM nanopartices}

The physical and chemical aggregation state of TLM was evaluated using UV and Fourier transform infrared (FTIR) spectroscopy. The FTIR spectrums of TLM and drug loaded chitosan NPs (freeze dried) were obtained using spectrometer (Perkin Elmer). A total of $2 \mathrm{mg}$ of sample was mixed with $100 \mathrm{mg}$ of dry potassium bromide $(\mathrm{KBr})$ and the mixture was ground into fine powder using a mortar before compressing into (KBr) disk under a hydraulic press at 10,000 psi. Each $\mathrm{KBr}$ disk was then scanned at $4 \mathrm{~mm} / \mathrm{s}$ at a resolution of $2 / \mathrm{cm}$ over a wave number region of $400-4000 / \mathrm{cm}$ using IR solution (software ver. 1.10). The characteristics peaks of functional groups in the drug samples were determined and compared with pharmacopoeial standards, and the 
possible interactions between drug and excipients were analyzed by obtained data. The electronic configuration of TLM NPs was elucidated by a UV spectrophotometer (UV 1700, Shimadzu, Japan). Lyophilized DTX-NCs were dispersed in triple-distilled water $(3.0 \mathrm{~mL})$ and scanned in the range from 200 to $400 \mathrm{~nm}$. The UV spectrum of pure TLM was taken after solubilizing it in methanol.

\section{Evaluation studies}

\section{Dissolution studies}

In-vitro drug release study for optimized formulations of TLM loaded polymeric NPs was conducted in triplicate by equilibrium dialysis membrane method. The amount of drug release from the formulation was measured using spectroscopic method. The experiment was performed by taking specified volume of formulation in hermetically sealed dialysis membrane. The dialysis bag was suspended in $\mathrm{pH} 7.4$ phosphate buffer saline (PBS) at $37^{\circ} \mathrm{C}$ being stirred at $240 \mathrm{rpm}$. Samples were collected at predetermined time points, and subsequently, media was replenished with pH 7.4 PBS after each sampling to maintain sink conditions.

\section{In vivo studies}

The experiments were carried out using adult male animals spontaneously hypertensive rat (SHRs) (225-250 g, 8-9 weeks old) procured from the laboratory animal services division of Central drug research Institute, Lucknow, India. Experiments were performed according to internationally followed ethical standards and approved by the Institutional animal ethics committee. They were kept in a polyacrylic cage $(22.5 \mathrm{~cm} \times 37.5 \mathrm{~cm})$ and were maintained under standard housing conditions $\left(24-27^{\circ} \mathrm{C}\right.$ and humidity $\left.60-65 \%\right)$ with a $12 \mathrm{hrs}$ light and dark cycle. They were fed a standard chow diet and water were available but were withdrawn $1 \mathrm{hr}$ before administration of drugs till completion of the trial. After the 1-week acclimatization period, animals were used of experiments, and all efforts were made to minimize animal suffering.

The animals were divided into the following three groups (TLM dose, $5 \mathrm{mg} / \mathrm{kg})$ :

- Group I: Treatment TLM (control group)

- Group II: Blank formulation (CMC-TLM)

- Group III: Formulation (CMC-TPP-TLM).

Measurement of blood pressure (BP) and heart rate (HR) using the telemetry system SHRs and maintained at $37^{\circ} \mathrm{C}$ on a servo controlled, heated rodent operating table. SHRs had a BP catheter attached to a telemeter inserted into their abdominal aorta. Hemodynamic data were measured over a 10 seconds interval every 5 minutes.

Dose 1 was used for vehicle-treated control. BP (mmHg) and HR (beats/min) were measured. Each treatment by single injection $(n=6)$ was performed with an interval of several days between each injection for washout and return to higher systolic BP (SBP) (200 $\mathrm{mmHg}$ ). Mean arterial pressure and HR were recorded continuously in telemetered rats and data were collected over $24 \mathrm{hrs}$ after injection.

\section{Cytotoxicity study}

\section{MTT assay}

Non-cytotoxic dose of chitosan, formulation, and combination of chitosan + formulation was identified in HaCaT, MCF-7, A549, and HepG2 human cell lines. Cytotoxicity assessment was done using standard endpoint, i.e., tetrazolium bromide MTT assay. In brief, cells $\left(1 \times 10^{4}\right.$ cells/well) were seeded in 96-well tissue culture plates and incubated in the $\mathrm{CO}_{2}$ incubator for $24 \mathrm{hrs}$ at $37^{\circ} \mathrm{C}$. Then, the medium was aspirated and cells were exposed to medium containing either of chitosan, formulation, and combination of chitosan + formulation $(0.001-100 \mu \mathrm{g} / \mathrm{ml})$ for $24-96 \mathrm{hrs}$ at $37^{\circ} \mathrm{C}$ in $5 \% \mathrm{CO}_{2}-95 \%$ atmosphere under high humid conditions. Tetrazolium salt ( $10 \mu \mathrm{l} /$ well; $5 \mathrm{mg} / \mathrm{ml}$ of stock in PBS) was added $4 \mathrm{hrs}$ before completion of respective incubation periods. At the completion of incubation period, the reaction mixture was carefully taken out and $200 \mu \mathrm{l}$ of culture grade DMSO was added to each well. The content was mixed well by pipetting up and down several times until dissolved completely. Plates were then incubated for 10 minutes at room temperature and color was read at $550 \mathrm{~nm}$ using multiwell microplate reader (Synergy HT, Bio-Tek, USA). The unexposed sets were also run parallel under identical conditions that served as a basal control.

\section{Neutral red uptake (NRU) assay}

The assay was carried out following the protocol described earlier by Siddiqui et al. [54]. Cells were exposed to compound in identical experimental setup as to MTT assay. On the completion of incubation period, medium was aspirated and NRU salt $(50 \mu \mathrm{M} / \mathrm{mL}$ in medium) was added $100 \mu \mathrm{l}$ per well plate and incubated for $3 \mathrm{hrs}$. Then, the reaction mixture was carefully taken out and plates were washed with washing solution $\left(100 \mu \mathrm{l} /\right.$ well) containing $1 \% \mathrm{CaCl}_{2}(\mathrm{w} / \mathrm{v})$ and $0.5 \%$ Formaldehyde for $\mathrm{HCHO}(\mathrm{v} / \mathrm{v})$ to remove unincorporated dye. Washing solution was removed and mixture of $200 \mu \mathrm{l} ; 1 \%$ acetic acid and $50 \%$ ethanol was added. The plates were kept on rocker shaker for $10 \mathrm{~min}$ at room temperature and then analyzed at $540 \mathrm{~nm}$ using multi-well microplate reader (Synergy HT, Bio-Tek, USA). Unexposed sets were also run under identical condition and served as control.

\section{Lactate dehydrogenase ( $\mathrm{LDH}$ ) release assay}

LDH release assay is a method to measure the membrane integrity as a function of the amount of cytoplasmic LDH released into the medium. The assay was carried out using readymade commercially available LDH assay kit for in vitro cytotoxicity evaluation (TOX-7, Sigma St. Louis, MO., USA). The assay was based on the reduction of nicotinamide adenine dinucleotide (NAD) by the action of LDH. The resulting reduced NAD $\left(\mathrm{NADH}^{+}\right)$was utilized in the stochiometric conversion of a tetrazolium dye. The resulting colored compound was measured using multiwell plate reader at wavelengths 490 and $690 \mathrm{~nm}$. In brief, the cells were exposed with $(0.001-100 \mu \mathrm{g} / \mathrm{ml})$ for different time periods after the completion of respective time periods the cells were processed for LDH release assay similar to MTT assay. Culture plates were removed from $\mathrm{CO}_{2}$ incubator as per the experimental schedule and centrifuged at $250 \times g$ for 4 minutes. Then, supernatant of each well was transferred to a fresh flat bottom 96 well culture plate and processed further for enzymatic analysis as per the manufacturer's instructions.

\section{RESULTS AND DISCUSSIONS}

\section{Characterization studies}

\section{FTIR analysis}

FTIR study was conducted to characterize any possible interaction between drug and CMCS NPs. The characteristic peaks at 3420/cm $(0-\mathrm{H}$ stretching and $\mathrm{N}-\mathrm{H}$ stretching vibrations), $1583 / \mathrm{cm}$ (corresponding to the amino groups), $1645,1548 / \mathrm{cm}$ (amide I and amide II of amino group), and 1076/cm (C-O-C stretching vibration) confirms the formation of CMCS, as shown in Fig. 2.

\section{$D L S$}

The hydrodynamic diameter of CMCS NPs are measured by DLS is $150 \pm 10 \mathrm{~nm}$, whereas that of TLM loaded NPs is $160 \pm 10 \mathrm{~nm}$ as shown in Fig. 3. Results representing that there is no big change between the two types of NPs, which demonstrates that the size distribution are not significantly affected during the encapsulation of TLM. In physiological conditions, the NPs are very stable and the stability was maintained for 12 days. In the stability study, on aggregation or precipitation of NPs was observed during the course of storage. Moreover, changes in particle size of the NPs of the study were very negligible. Zeta potential

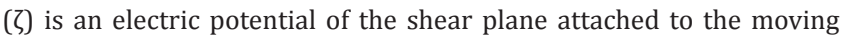
particles in the medium and it is generally utilized for the prediction of stability of nanosuspensions. The decrease in zeta potential value with decrease in concentration of stabilizer may be attributed to the inability of stabilizer to prevent particle agglomeration at lower concentrations. 
The reults of the optimized batches of TLM loaded nanosuspension depicted the zeta potential values of more than $30 \mathrm{mV}$, which suggested physical stable formulation developed [9].

\section{TEM}

The characterization of morphology and size of the nanopaticles are performed using the TEM technique. TEM micrographs were obtained

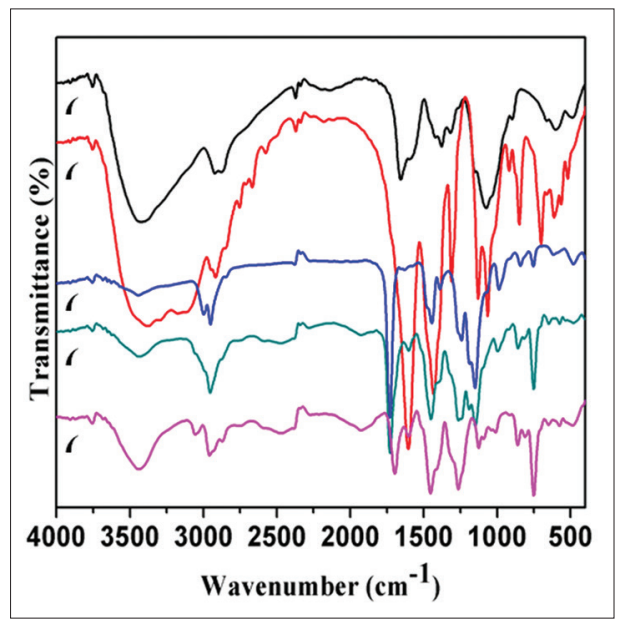

Fig. 2: Fourier transform infrared spectra of carboxymethyl chitosan (CMCS), $\mathrm{CaCl}_{2}$, telmisartan (TLM) and CMCS-TLM

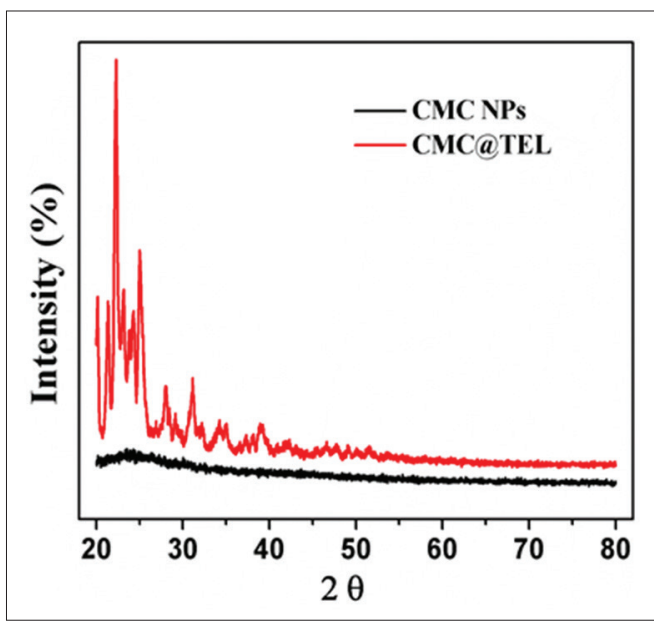

Fig. 3: Hydrodynamic diameter of telmisartan loaded nanoparticles measured by dynamic light scattering
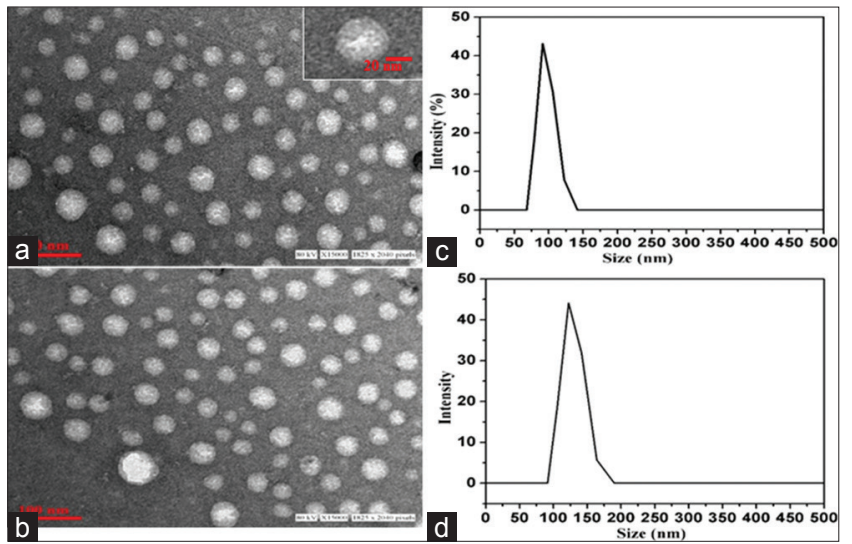

Fig. 4: (a-d) Transmission electron microscopy photograph of optimized batch of telmisartan loaded nanosuspension with an acceleration voltage of $200 \mathrm{kV}$. A drop of sample solution was placed onto a copper grid with carbon, taped with a filter paper to remove surface solvent, and air-dried for 2 minutes. The study results are shown in Fig. 4

\section{SEM}

SEM was used to determine the particle size and surface morphology of the NPs. The study reveals that the surface of the NPs was smooth and

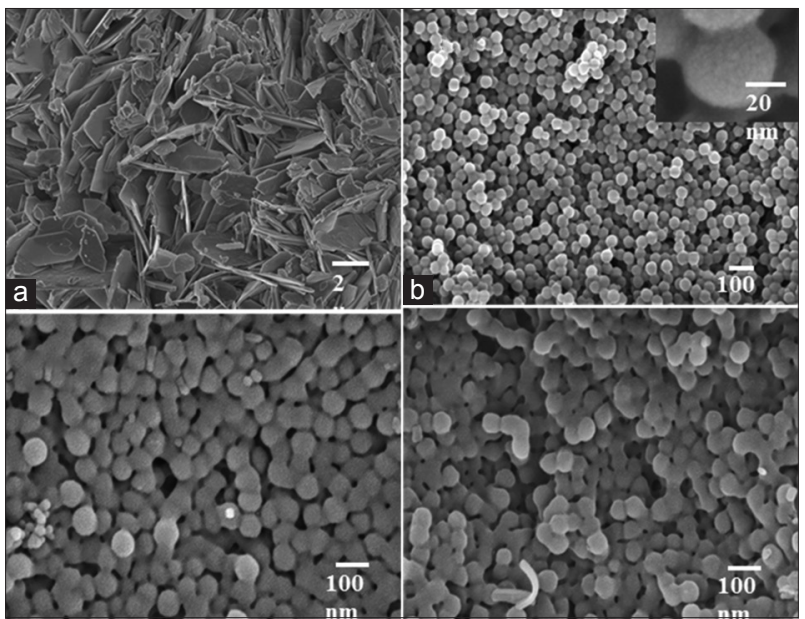

Fig. 5: (a-b) Scanning electron microscopy microphotographs of telmisartan nanoparticles

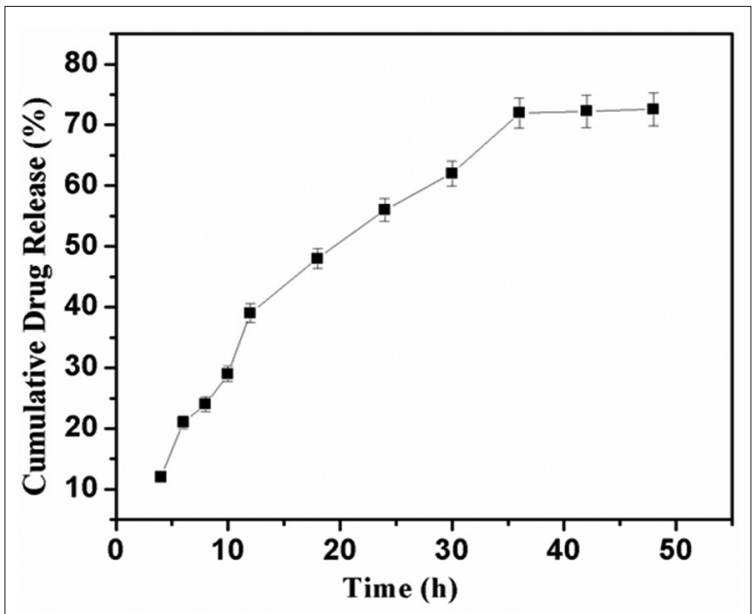

Fig. 6: In-vitro release studies of telmisartan nanoparticles

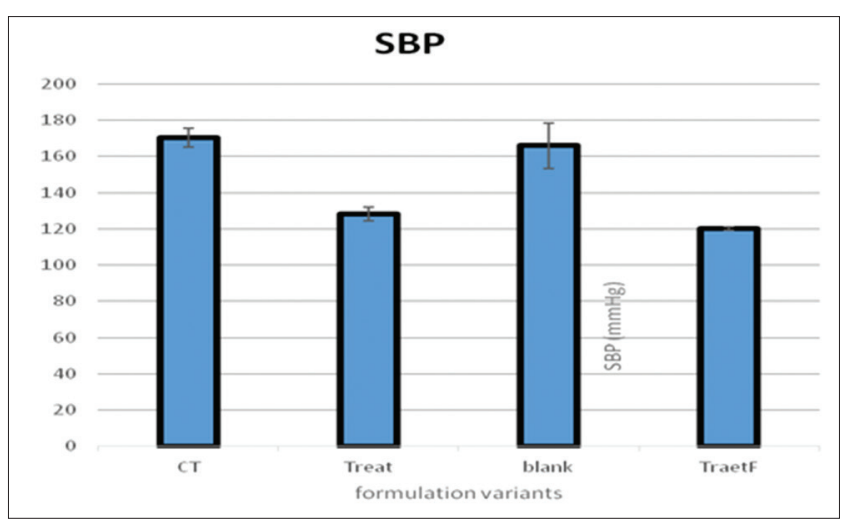

Fig. 7: The effect of telmisartan treatment on blood pressure in spontaneously hypertensive rats 


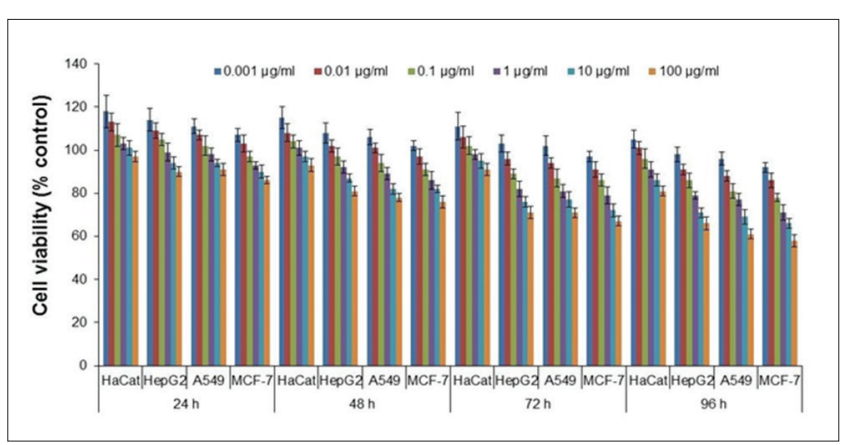

Fig. 8: 3-(4,5-dimethylthiazol-2-yl)-2,5-diphenyltetrazolium bromide assay of chitosan + formulation

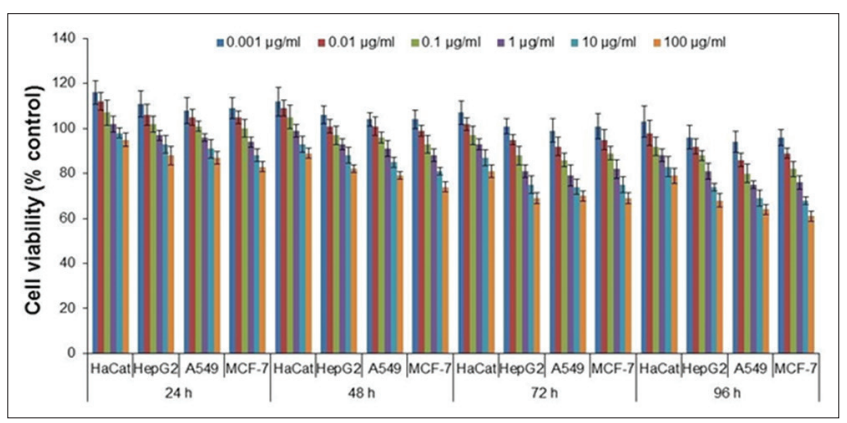

Fig. 9: Neutral red uptake assay of chitosan+ formulation

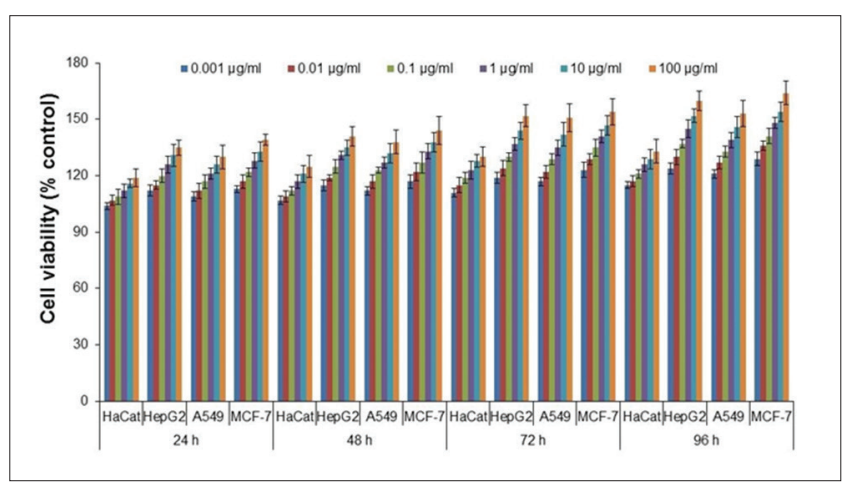

Fig. 10: Lactate dehydrogenase assay of chitosan + formulation

no aggregate were found from the sample used for SEM analysis. The particle size of the NPs was found to be $100 \mathrm{~nm}$. The study results are shown in Fig. 5.

\section{Evaluation studies}

In-vitro drug release studies

The In-vitro release studies were carried out using dialysis membrane. The cumulative percentage drug release after $48 \mathrm{hrs}$ was found to be. The significantly lower values of TLM loaded nanosuspension suggested market improvement in dissolution rate of by the developed nanosized formulation in dissolution velocity of TLM NPs could be attributed to the reduction in particle size, in surface area, and decrease in diffusion distance, whereas the incomplete drug release of drug particles could be attributed to the large crystal size Fig. 6 .

\section{In vivo studies}

To determine the effect of TLM treatment on BP in SHR rats, we measured the SBP of the group rats every week. The baseline SBP in SHRs was $170 \pm 2 \mathrm{~mm} \mathrm{Hg}$ which was much higher than in WKY (121 $\pm 1 \mathrm{mmHg}, \mathrm{p}<0.001)$. Administration of nano TLM in the dose of $5 \mathrm{mg} / \mathrm{kg}$ concentration showed a significant decrease in SBP than the administration of $5 \mathrm{mg} / \mathrm{kg}$ TLM showed a substantial decrease in SBP at the end of week, showed significant reduction when compared with the vehicle control SHR rats Fig. 7.

\section{Cytotoxicity study}

\section{MTT assay}

The highlights of the data of cytotoxicity activity of test compounds on independent exposure as well as in combination are summarized in Figs. 8-10. A time and dose-dependent decrease in percent cell viability was observed in all the cells used in the study. However, none of the concentration could induce loss of all viability upto statistically significant level in any cell type. HaCat, a normal human cell line was used as positive control against the human cancer cell lines of different origin viz., HepG2 (hepatoma cells), A549 (lund epithelium carcinoma cells) and MCF-7 (human breast adenocarcinoma cells). However, no cell specific changes could be recorded and there was a non-significant loss of cell viability with more or less equal magnitude in all the cell types. Hence, the effect of chemicals could be speculated due to cytostatic responses, not due to anti-cancer activity. Although the combination of both the test compounds increases the magnitude of percent cell viability loss, could not attain the significant levels. In the present investigations, both the test compounds were found to be noncytotoxic/non anti-carcinogenic upto $100 \mu \mathrm{g} / \mathrm{ml}$ concentration for a long term exposure, i.e., till $96 \mathrm{hrs}$ in human cancer cells of different origin. Even the combination of these two test compounds were also not able to brought the effect to the significant level. In cytotoxic investigations, both the test compounds (CMCS, CMCS-TLM NP) were found to be noncytotoxic/non-anti-carcinogenic upto $100 \mu \mathrm{g} / \mathrm{ml}$ concentration for a long term exposure, i.e., till $96 \mathrm{hrs}$ in human cancer cells of different origin. Even, the combination of these two test compounds were also not able to brought the effect to the significant level.

\section{CONCLUSION}

In summary, we have developed a new approach toward the delivery of poorly water soluble drug TLM by CMCS NPs. The particles having a good drug loading content and drug encapsulation efficiency. The cytotoxicity of the synthesized NPs are also very less.

\section{ACKNOWLEDGMENT}

Authors would like to thank Amity University, Lucknow for providing research facilities. CSIR-CDRI, Lucknow is acknowledged for providing the support for research work.

\section{REFERENCES}

1. Kreuter J. Nanoparticles based drug delivery systems. J Control Release 1991;16:169-76.

2. Grenha A, Seijo B, Remuñán-López C. Microencapsulated chitosan nanoparticles for lung protein delivery. Eur J Pharm Sci 2005;25(4-5):427-37.

3. Krishna RS, Shivakumar GH, Gowda DV, Banerjee S. Nanoparticles: A novel colloidal drug delivery system. Indian J Pharm Educ Res 2006;40(1):15-21

4. Aktas Y, Andrieux K, Alonso MJ, Calvo P, Gürsoy RN, Couvreur P, et al. Preparation and in vitro evaluation of chitosan nanoparticles containing a caspase inhibitor. Int J Pharm 2005;298(2):378-83.

5. Pan Y, Li YJ, Zhao HY, Zheng JM, Xu H, Wei G, et al. Bioadhesive polysaccharide in protein delivery system: Chitosan nanoparticles improve the intestinal absorption of insulin in vivo. Int $\mathrm{J}$ Pharm 2002;249(1-2):139-47.

6. Ma Z, Lim TM, Lim LY. Pharmacological activity of peroral chitosaninsulin nanoparticles in diabetic rats. Int J Pharm 2005;293(1-2):271-80.

7. Vauthier C, Dubernet C, Chauvierre C, Brigger I, Couvreur P. Drug delivery to resistant tumors: The potential of poly(alkyl cyanoacrylate) nanoparticles. J Control Release 2003;93(2):151-60.

8. Liang HF, Chen CT, Chen SC, Kulkarni AR, Chiu YL, Chen MC, et al. Paclitaxel-loaded poly(gamma-glutamic acid)-poly(lactide) nanoparticles as a targeted drug delivery system for the treatment of liver cancer. Biomaterials 2006;27(9):2051-9.

9. Sheikh FA, Barakat NA, Kanjwal MA, Aryal S, Khil MS, Kim HY. 
Novel self-assembled amphiphilic poly(epsilon-caprolactone)-graftedpoly(vinyl alcohol) nanoparticles: Hydrophobic and hydrophilic drugs carrier nanoparticles. J Mater Sci Mater Med 2009;20(3):821-31.

10. Mitra S, Gaur U, Ghosh PC, Maitra AN. Tumour targeted delivery of encapsulated dextran-doxorubicin conjugate using chitosan nanoparticles as carrier. J Control Release 2001;74(1-3):317-23.

11. López-León T, Carvalho EL, Seijo B, Ortega-Vinuesa JL, Bastos-González D. Physicochemical characterization of chitosan nanoparticles: Electrokinetic and stability behavior. J Colloid Interface Sci 2005;283(2):344-51.

12. Illum L. Chitosan and its use as a pharmaceutical excipient. Pharm Res 1998;15(9):1326-31.

13. Dodane V, Vilivalam VD. Pharmaceutical applications of chitosan. Pharm Sci Technol Today 1998;1:246-53.

14. Felt O, Buri P, Gurny R. Chitosan: A unique polysaccharide for drug delivery. Drug Dev Ind Pharm 1998;24(11):979-93.

15. Yao KD, Peng T, Yin YJ, Xu MX. Microcapsules/microspheres related to chitosan. J Macromol Sci Rev Macromol Chem Phys 1995;35:155-80.

16. Kas HS. Chitosan: Properties, preparations and application to microparticulate systems. J Microencapsul 1997;14(6):689-711.

17. Muzzarelli RA, Jeuniauk C, Gooday GW. Chitin in Nature and Technology. New York: Plenum; 1986.

18. Sjak-Braek G, Anthonsen T, Sandford P. Chitin and Chitosan. New York: Elsevier; 1992

19. Sannan T, Kurita K, Iwakura Y. Studies on chitin: Effect of deacetylation on solubility. Makromol Chem 1976;177:3589-600.

20. Nicol S. Life after death for empty shells. New Sci 1991;129:46-8.

21. Arai K, Kinumaki T, Fujita T. Toxicity of chitosan. Bull Tokai Reg Fish Lab 1968;43:89-94.

22. Chandy T, Sharma CP. Chitosan - As a biomaterial. Biomater Artif Cells Artif Organs 1990;18(1):1-24.

23. Hou WM, Miyazaki S, Takada M, Komai T. Pharmaceutical application of biomedical polymers. Part XVI. Sustained release of indomethacin from chitosan. Chem Pharm Bull 1985;33:3986-92.

24. Miyazaki S, Ishii K, Nadai T. Pharmaceutical application of biomedical polymers. Part IV. The use of chitin and chitosan as drug carriers. Chem Pharm Bull 1981;29:3067-9.

25. Kawashima Y, Handa T, Kasai A, Takenaka H, Lin SY, Ando Y. Novel method for the preparation of controlled-release theophylline granules coated with a polyelectrolyte complex of sodium polyphosphatechitosan. J Pharm Sci 1985;74(3):264-8.

26. Miyazaki S, Yamaguchi H, Yokouchi C, Takada M, Hou WM. Sustainedrelease and intragastric-floating granules of indomethacin using chitosan in rabbits. Chem Pharm Bull (Tokyo) 1988;36(10):4033-8

27. Sawayanagi Y, Nambu N, Nagai T. Use of chitosan for sustainedrelease preparations of water-soluble drugs. Chem Pharm Bull (Tokyo) 1982;30(11):4213-5.

28. Shiraishi S, Imai T, Otagiri M. Controlled release of indomethacin by chitosan- polyelectrolyte complex: Optimizationand in vivo/in vitro evaluation. J Control Release 1993;25:217-25.

29. Lehr CM, Bouwstra JA, Schacht EH, Junginger HE. In vitro evaluation of mucoadhesive properties of chitosan and some other natural polymers. Int J Pharm 1992;78:43-8.

30. Luehen HL, Lehr CM, Rentel CO, Noach AB, Boer AG, Verhoef JC, et al. Bioadhesive polymers for the peroral delivery of peptide drugs. $\mathrm{J}$ Control Release 1994;29:329-38.

31. Illum L, Farraj NF, Davis SS. Chitosan as a novel nasal delivery system for peptide drugs. Pharm Res 1994;11(8):1186-9.

32. Imai T, Shiraishi S, Saito H, Otagiri M. Interaction of indomethacin with low molecular weight chitosan and improvements of some pharmaceutical properties of indomethacin by low molecular weight chitosans. Int J Pharm 1991;67:11-20.

33. Pavanetto F, Genta I, Giunchedi P, Conti B, Conte U. Spray-Drying for the Preparation of Chitosan Microspheres. Proceeding International Symposium Controlled Release of Bioactive Materials. $21^{\text {st }} ; 1994$.

34. Sawayanagi Y, Nambu N, Nagai T. Enhancement of dissolution properties of prednisolone from ground mixtures with chitin or chitosan. Chem Pharm Bull 1983;31:2507-9.

35. Gallo JM, Hassan EE. Receptor-mediated magnetic carriers: Basis for targeting. Pharm Res 1988;5(5):300-4.

36. Hassan EE, Parish RC, Gallo JM. Optimized formulation of magnetic chitosan microspheres containing the anticancer agent, oxantrazole. Pharm Res 1992;9(3):390-7

37. Artursson P, Lindmark T, Davis SS, Illum L. Effect of chitosan on the permeability of monolayers of intestinal epithelial cells (Caco-2). Pharm Res 1994;11(9):1358-61.

38. Berscht PC, Nies B, Liebendörfer A, Kreuter J. Incorporation of basic fibroblast growth factor into methylpyrrolidinone chitosan fleeces and determination of the in vitro release characteristics. Biomaterials 1994;15(8):593-600.

39. Yinsong W, Lingrong L, Jian W, Zhang Q. Preparation and characterization of self-aggregated nanoparticles of cholesterol- modi We O-carboxymethyl chitosan conjugates. Carbohydr Polym 2007;69:597-606.

40. Wienen W, Entzeroth M, Jacobus A, Stangier J, Busch U, Ebner T. A review on telmisartan: A novel long - Angiotensin II - Receptor antagonist. Cardiovasc Durg Rev 2000;18(2):127-54.

41. Kothawade SN, Kadam NR, Aragade PD, Baheti DG. Formulation and charcterization of telmisartan solid dispersions. Int J Pharm Tech Res 2010;2(1):341-7.

42. Brahmankar DM, Sunil JB. Biopharmaceutics and Pharmacokinetics: A Treatise. $1^{\text {st }}$ ed. New Delhi: Vallabh Prakashan; 2005. p. 27-30.

43. Christian L, Jennifer D. Improving drug solubility for oral delivery using solid dispersions. Eur J Pharm Biopharm 2000;5:47-8.

44. Garekani HA, Sadeghi F, Badiee A, Mostafa SA, Rajabi-Siahboomi AR. Crystal habit modifications of ibuprofen and their physicomechanical characteristics. Drug Dev Ind Pharm 2001;27(8):803-9.

45. Nandita Das G, Sudip Das K. Formulation of Poorly Soluble Drugs. Drug Delivery Report Spring/Summer; 2006. p. 52-5.

46. James S, Boylan JC. Encyclopedia of Pharmaceutical Technology. $2^{\text {nd }}$ ed. New York, United States: Taylor \& Francis Inc.; 2002. p. 1641-7.

47. Leuner C, Dressman J. Improving drug solubility for oral delivery using solid dispersions. Eur J Pharm Biopharm 2000;50(1):47-60.

48. Modi A, Tayade P. Enhancement of dissolution profile by solid dispersion (kneading) technique. AAPS PharmSciTech 2006;7(3):68.

49. Sathiya S, Babu CS. Telmisartan alleviates nitrosative stress in turn dopaminergic degeneration in mice MPTP model of parkinsonism Biochemical and histopathological evidences. Int J Pharm Pharm Sci 2015;7(6):97-101.

50. Hyma P, Chandra A, Abbulu K. Formulation and characterization of telmisartan self microemulsifying drug delivery system. Int J Pharm Pharm Sci 2014;6(1):120-5.

51. Patel B, Parikh RH, Swarnkar D. Enhancement of dissolution of telmisartan through use of solid dispersion technique - surface solid dispersion. J Pharm Bioallied Sci 2012;4 Suppl 1:S64-8.

52. Zhang Y, Jiang $\mathrm{T}$, Zhang $\mathrm{Q}$, Wang $\mathrm{S}$. Inclusion of telmisartan in mesocellular foam nanoparticles: Drug loading and release property. Eur J Pharm Biopharm 2010;76(1):17-23

53. Chen XG, Park HJ. Chemical characteristics of O-carboxymethyl chitosans related to the perpartion condition. Carbohydrate 2003;53(4):355-9

54. Siddiqui MA, Singh G, Kashyap MP, Khanna VK, Yadav S, Chandra D, et al. Influence of cytotoxic doses of 4-hydroxynonenal on selected neurotransmitter receptors in PC-12 cells. Toxicol In Vitro 2008;22(7):1681-8. 